\section{Teaching Sustainable Design: A Hands-on Interdisciplinary Model}

\author{
Baldev Lamba ${ }^{1}$ and Grace Chapman ${ }^{2,3}$
}

ADDITIONAL INDEX WORDS. collaboration, holistic, conservation, experiential learning

SUMMARY. Students and instructors from the Department of Landscape Architecture and Horticulture, located on the Temple University Ambler Campus, collaborated on the design and construction of an exhibit for the 2009 Bella Italia Philadelphia Flower Show. The design of the exhibit, inspired by Italian traditions, promoted sustainable principles and practices through the use of indigenous and recycled materials and conservation of natural resources. Temple University's exhibit received five awards, including the American Horticultural Society Environmental Award and the Garden Club Federation of Pennsylvania Award for Conservation. This article documents the interdisciplinary and hands-on teaching model used in creating and implementing a sustainable design, as well as the results of the followup student surveys about the lessons learned and public responses to the exhibit.

$\mathrm{T}$ his article focuses on designing and building a major exhibit at the Bella Italia-themed 2009 Philadelphia Flower Show, which took place on Mar. 1st through 8th, 2009. Hosted by the Pennsylvania Horticultural Society (PHS), the annual event is the largest indoor flower show in the world-spread over 10 acres and attracting more than 250,000 visitors - and is an important venue for promoting new ideas for horticulture and landscape design (Levine and Rogers, 2003). This project was undertaken by the Department of Landscape Architecture and Horticulture (LA/Hort), located at the Temple University Ambler (TUA) campus, which is also home to the Landscape Arboretum at TUA that is an integral part of LA/Hort. Temple University has a long history of participation in the Philadelphia Flower Show, dating back to the 1970s and garnering numerous awards. Funded with financial support from Temple University, these exhibits, in the educational category of the Philadelphia Flower Show, highlight a variety of historical, cultural, and environmental themes representing the scope, vision, and mission of LA/Hort.

${ }^{1}$ Associate Professor of Landscape Architecture, Temple University, 580 Meetinghouse Road, Ambler, PA 19002-3999

${ }^{2}$ Horticulture and Landscape Arboretum Supervisor and Adjunct Professor, Temple University, 580 Meetinghouse Road, Ambler, PA 19002-3999

${ }^{3}$ Corresponding author. E-mail: grace.chapman@temple. edu.
Taking inspiration from Italian gardening and farming traditions, our exhibit embodied three critical aspects of LA/Hort: a long tradition of hands-on education, the integration of landscape design and horticulture, and the mission of advocating sustainability.

Increased student interest in sustainability coupled with societal awareness and the evolving public policy commitment to green design has intensified demands for greater involvement of design and horticulture schools in teaching and research related to sustainability. Degree and certificate programs focused on sustainability are beginning to emerge at a number of design and horticulture schools, pointing to the rapid acceptance and importance of the sustainability paradigm. Many institutions of higher learning are promoting a variety of "green" and "sustainable" initiatives in a race to become leaders and models of transforming education and drawing resources dedicated to new research and outreach. Temple University has adopted the United Nations' definition of sustainability as "the ability to meet the needs of the present without compromising the ability of future generations to meet their own needs" to guide the work of its recently formed Office of Sustainability (Temple University, 2009). This entity is charged with implementing Temple University's goal to conserve resources, reduce our carbon footprint, support our ecosystems, and promote the use of regional resources. The Philadelphia Flower Show exhibit presented an opportunity to showcase and advance Temple University's commitment to sustainability in a very practical, easily accessible, and adaptable format.

Integrating disciplines is widely recognized as a highly desirable and effective teaching model that engenders holistic thinking and breaks down disciplinary boundaries. The interdisciplinary interaction of the LA/Hort programs for this project was critical to achieving our sustainability goals for the flower show. Klein (1990) defines interdisciplinary learning as the synthesis of two or more disciplines, establishing a new level of discourse and integration of knowledge. The term interdisciplinary is used variably as a concept, a methodology, a process, a way of knowing, and even a philosophy. It facilitates the development of enhanced critical thinking ability and metacognitive skills, and an understanding of the relationships among perspectives derived from different disciplines. Interdisciplinary/crosscurricular teaching can increase students' motivation for learning and their level of engagement. In contrast to learning skills in isolation, when students participate in interdisciplinary experiences, they see the value of what they are learning and become more actively engaged (Resnick, 1989).

The hands-on aspect of developing the exhibit introduced students to the many challenges related to budgets, real deadlines, and the logistics of the construction process. Adding a hands-on or experiential learning component to the more traditional verbal and visual teaching techniques enhances overall educational quality and promotes professional development

\begin{tabular}{llll}
\hline $\begin{array}{l}\text { Units } \\
\begin{array}{l}\text { To convert U.S. to SI, } \\
\text { multiply by }\end{array}\end{array}$ & U.S. unit & SI unit & $\begin{array}{l}\text { To convert SI to U.S., } \\
\text { multiply by }\end{array}$ \\
\hline 0.4047 & $\mathrm{acre}(\mathrm{s})$ & $\mathrm{Ha}$ & 2.4711 \\
0.3048 & $\mathrm{ft}$ & $\mathrm{M}$ & 3.2808 \\
1.6093 & mile(s) & $\mathrm{Km}$ & 0.6214
\end{tabular}


and competence. The quote "I hear and I forget - I see and I remember - I do and I understand," attributed to Confucius, underscores the importance of experiential learning.

Our exhibit received awards from many prestigious organizations, testifying to our mission of conservation, environmental responsibility, and sustainability. This article offers insights for an effective interdisciplinary, hands-on teaching model in creating sustainable designs, with an understanding of its potential challenges. Based on a survey of the students, the article also includes lessons learned, as well as a sampling of public response to the exhibit.

\section{Learning objectives}

With the overall goal of enhancing student learning, responding to the Italian theme of the Philadelphia Flower Show, and the educational mission of our department, the learning objectives for the project included the following: 1) developing a contemporary and indigenous interpretation of the concepts and ideas embodied in the Italian Renaissance gardens and farming traditions; 2) incorporating sustainable principles and practices, including water conservation, local food production, and using indigenous, salvaged, recycled, or recyclable materials; 3 ) creating a hands-on learning experience for the students; 4) meeting the educational agenda of our exhibit and developing effective means of informing the public about ways and benefits of using sustainable practices in their gardens; 5) using construction materials and building techniques for easy reuse or responsible disposal at the end of the show.

Through lectures and reading assignments, students learned about the underlying ideas and qualities of Italian Renaissance gardens, along with their modern interpretations. They discovered how these gardens were an integral part of the surrounding architecture and landscape, and how their designs responded to the social needs of the inhabitants. Water was used as the unifying element, along with evergreens and masonry, to create terraced parterres in formal arrangements with framed views. The students explored creative ways of using these basic design principles and elements in discovering artistic expressions of sustainable design that would invite visitors to stop, look, listen, feel, and think.

A sustainable design approach demands a holistic evaluation of the environmental impact of every decision and action. The responsibility for the selection of materials goes beyond the usual what and how, and includes having a complete knowledge of the manufacturing process of a specific product, the impact on non-renewable resources, the potential for recycling, and safe disposal options.

While virtually nothing can be $100 \%$ sustainable, we increased the level of sustainability in our design by using indigenous, reused, recycled, or recyclable materials throughout our exhibit to the greatest extent possible, within the constraints of a temporary installation. Every design and construction decision was carefully examined and evaluated to minimize waste and maximize conservation.

\section{Teaching model}

This project involved faculty and students from the third year Landscape Architecture Studio and the Directed Studies in Horticulture course in Fall 2008 and Spring 2009. In Summer 2008, much of the preparation and research for the project was undertaken by the instructors to meet the mid-September PHS deadlines for the submission of design concepts. The LA studio involvement took up part of the Fall 2008 semester and continued through the Spring 2009 semester. Project work, especially for greenhouse production, continued when the students were away for the winter break and was managed by the horticulture staff of the Landscape Arboretum at TUA.

The LA studio met on a regular Monday, Wednesday, Friday schedule for a 3.5-h session, while the Hort course had periodic meetings on an as-needed basis for planning, as well as $1 \mathrm{~d}$ per week for hands-on work in the greenhouse. Having the two groups together in one place at the same time proved to be much harder than expected. Using a fixed meeting time in which the Hort course and the LA studio overlapped would have improved coordination and collaboration between the two groups.

The success of this teaching model, which spanned one summer and two academic semesters, required effective communications, coordination, teamwork, flexibility, and organizational and management skills. The time needed to complete the project went well beyond the regular class schedules. At times it interfered with other classes and courses, requiring special accommodations from other instructors. The studio had to operate more like a professional office, with daily contacts, rigorous schedules, responsibilities, and hard deadlines. All of this provided the students with the invaluable experience of taking projects from concept to completion.

Forty students and four faculty members from LA/Hort programs were involved with this project. This core group, assisted by other administrators and staff, participated in the design, construction, and maintenance of this exhibit. LA Professor B. Lamba was responsible for the overall management of the project, leading 30 students in the LA junior design studio. He was assisted by LA Professor R. Kuper in the Fall 2008 semester and teamed up with Adjunct LA Professor M. Lofurno, a practitioner with design/build expertise, in the Spring 2009 semester. Working with 10 students from different levels of LA/Hort programs, Horticulture Supervisor G. Chapman coordinated all horticultural components as part of the Directed Studies in Horticulture course. Staff horticulturists S. Chlebda, M. Miller, and $\mathrm{K}$. Butler managed the plant forcing and greenhouse operations and participated in installation.

\section{Fall 2008: Planning and design}

Working in groups of two, the students in the LA junior studio spent the first 3 weeks of the semester developing themes and design alternatives, presenting their ideas, and refining the final design concept. This process was guided by the overall goals established for the project. The group settled on Green Renaissance Revival of Sustainable Living as the theme and title of the exhibit.

The Hort course students spent the entire Fall 2008 semester preparing plant lists, sourcing plant material, starting seeds, and propagating plants. They focused on colors, sizes, forms, and textures suitable for the design intent, as well as meeting overall goals of sustainability. 
Evoking the Italian farming and Renaissance gardens, the layout for this $36-\mathrm{ft}$-long and 20 -ft-wide exhibit was a formal triaxial, three-parterre garden, surrounded by an aerial aqueduct. The raised parterres represented a kitchen garden, a dry garden, and an orchard garden, each with its own distinct water features. The architectural components included an aerial aqueduct, water features, a terrace wall, a green wall, a water table, garden walls, and paving. The exhibit design features are shown in the illustrative plan (Fig. 1) and section drawings (Figs. 2 and 3 ).

The central focal point was a water table flanked with green walls (Fig. 4). A green wall is a relatively recent design feature. Also referred to as living wall, biowall, or vertical garden, partially or completely covered with a green wall is a vertical structure,

vegetation, and it can be used indoors or outdoors, providing privacy, biodiversity, cooling, and air-filtering benefits.

Our design was a modern and sustainable adaptation of the elements of Italian gardens such as terraces, parterres, grand staircases, water features, and evergreens. Traditional stairways, common in the terraced Italian gardens, were represented by inclined water chutes, set behind the green walls. These received water from the aerial aqueduct and created waterfalls framing the water table. Copper gutters, inspired by the Roman aqueducts, implied the idea of rainwater harvesting and framed the entire exhibit. The "water table" concept was derived from the 16th century Villa Lante, which features a long masonry Pope's table with a water channel.

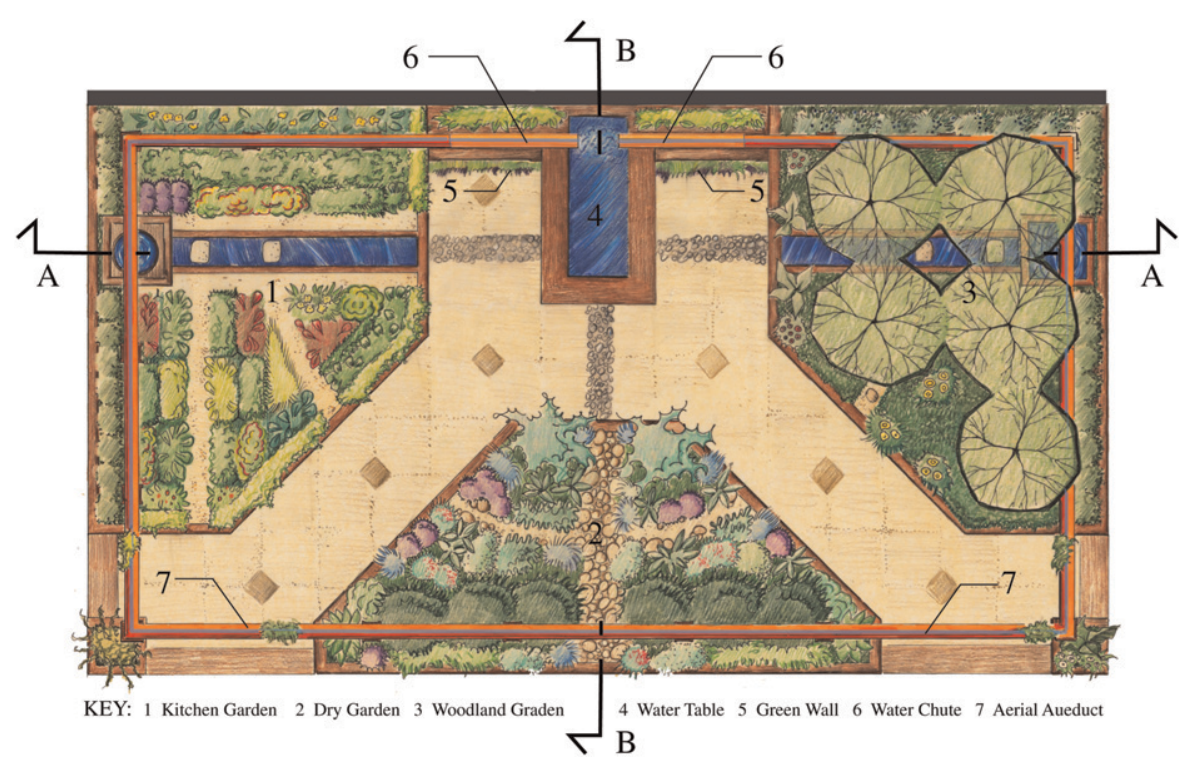

Fig. 1. Illustrative plan of Temple University's Green Renaissance-themed, 36-ftlong $(11.0 \mathrm{~m})$ and 20 -ft-wide $(6.1 \mathrm{~m})$ exhibit at the Philadelphia Flower Show (image credit: K. Whyte).

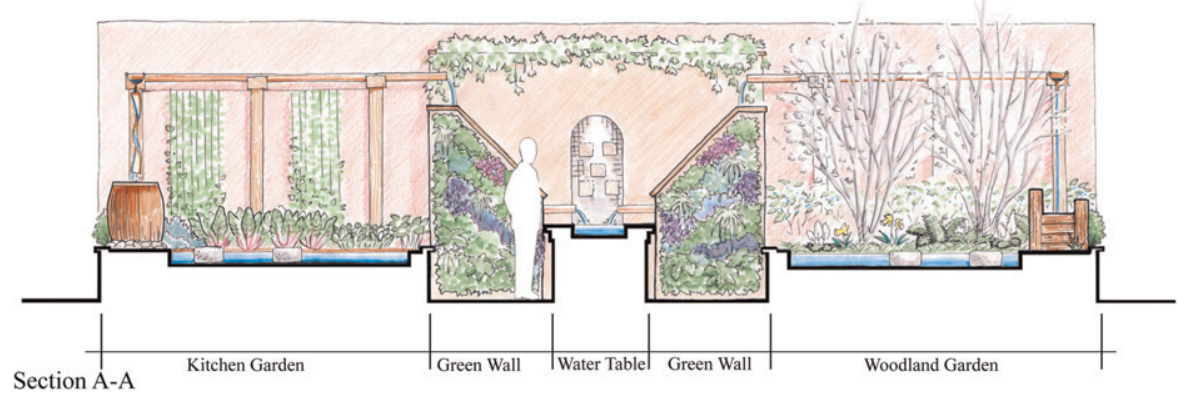

Fig. 2. Illustrative section A-A, running north-south, of the 2009 Temple University Philadelphia Flower Show exhibit (image credit: R. Irizarry).
The last 4 weeks of the Fall 2008 junior design studio were devoted to refining design themes, clarifying design intent, and selecting construction techniques and materials. LA students worked in groups on the following four components of the exhibit: 1) architectural features, 2) gardens, 3 ) paving and electrical, and 4 ) education and publicity.

Each group designated a coordinator responsible for representing the group at periodic project meetings, delegating tasks, reporting problems, and implementing time sheet and purchasing policies. Each group had smaller teams responsible for specific tasks involved in constructing each component. Through research and intensive design explorations, students analyzed and explored how every design feature could be adapted to our region, how these represented our sustainability mission for the exhibit, and how these concepts could be translated to the public.

The charm and appeal of the design came from using uncommon objects and materials in new and unexpected ways. Discarded pallet wood was revitalized by using eco-friendly stains to create the garden walls. A long-forgotten pull chain and hook, found in an old garage, served as a rain chain, an alternative to traditional gutter downspouts to collect rainwater. This created a distinct water element playfully directing water to the rocky streambed in the dry garden (Fig. 5). Twisted metal veins rescued from an old heater were used as a water feature, guiding shimmering water splashing into an old whiskey barrel in the kitchen garden. The top of the "water table" was built with salvaged rafter lumber from old houses in Philadelphia. In addition to meeting our recycling objectives, these improvised and esoteric materials were a huge draw with the visitors, generating enthusiastic reactions and comments.

It took a great deal of research to realize our sustainable goals in the production of educational materials. Using a local printing press, the signage, brochures, and fliers were made by a process called "computer to plate" printing, which eliminates the need for making films requiring many caustic chemicals. The paper, which contained $70 \%$ postconsumer waste, was untreated to facilitate recycling. 


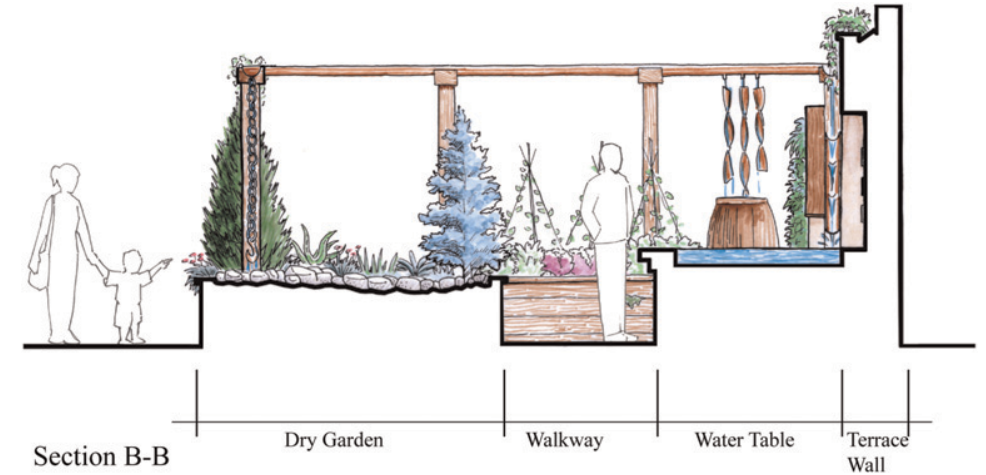

Fig. 3. Illustrative section B-B, running east-west, of the of the 2009 Temple University Philadelphia Flower Show exhibit (image credit: R. Irizarry).

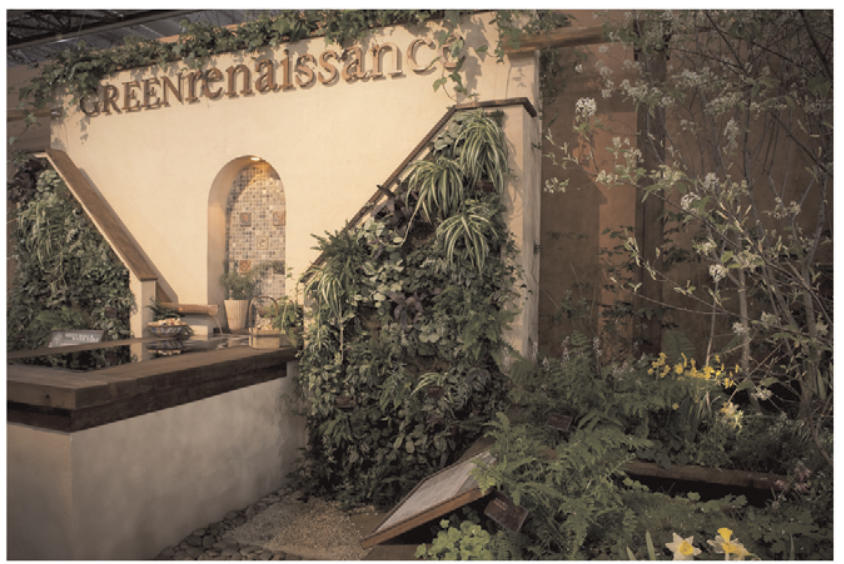

Fig. 4. A water table and tiled niche, flanked with green walls, serves as the central focal point of Temple University's 2009 Philadelphia Flower Show display (photo credit: B. Kelly).

The ink was soybean and linseed oil based, reducing the consumption of petroleum products and the disposal of harmful by-products.

Our goal of reuse after the show was achieved by well-thought-out construction strategies, such as using full-length lumber for the aqueduct posts, and using standard copper gutters for the aerial aqueduct to make it easier to use them in other projects at TUA. Similarly, as an alternative to joining wood using nails and glue, screws and bolts were used for easy disassembly and reuse.

The Hort course students researched plant material used in Italian gardens to choose plants hardy to our area and to support the design intent of various thematic gardens in the exhibit. Plants were further selected based on their non-invasive qualities, availability from local sources, and potential reuse in the Landscape Arboretum at TUA after the flower show.
In keeping with the design theme and low water requirements of the dry garden, plants with silver foliage and blue and purple flowers were selected for this garden. The edible theme of the kitchen garden displayed vegetables used in traditional American gardens that also had ornamental characteristics. The pleasant aromas from the herbs greatly added to the sensory experience of the exhibit, compelling many visitors to reach out to touch and smell the plants. The orchard garden was a naturalistic interpretation of Italian olive (Olea europaea) groves. The green wall was comprised of nonhardy plants to display a seasonal or indoor green wall. A sampling of the 135 plant species used in the display is illustrated in Table 1.

In growing for the flower show, many plants that would not normally bloom at the same time of year were forced to be at their peak during the first week of March. To accomplish this, the plants were grown through the winter and were forced to prematurely break dormancy (Fig. 6). This required a fine balance of cold treatments, heat, and light. Because of this delicate balance, contingency plans were built into the process. In general, twice as much plant material was grown than was projected to be needed for the display. This included having back-up plants in case plants were damaged in transit to the show, as well as back-up species if certain plants underperformed, did not force properly, or were damaged by pests and diseases.

After plant selection and sourcing, the plants were grown by horticulture staff assisted by the Hort class students in our TUA greenhouses. The students and staff were met with many challenges that demanded flexibility throughout the process. One of our goals was to source plants locally to reduce the need for transportation. However, many ideal plants were only available from sources outside of our region, requiring modifications to the plant lists. Pests and diseases were also a problem in the greenhouse during the forcing period. The most severe was a two-spotted spider mite (Tetranychus urtica) infestation that damaged many plants and wiped out a crop of 'Hidcote' lavender (Lavandula angustifolia). Powdery mildew (order Ersiphales) also caused our 'RADrazz' knockout roses (Rosa sp.) to be below aesthetic show standards. Both of these species had been main features of the dry garden, so we needed to use our back-up species of 'Rober's Lemon Rose', 'Dean's Delight', and 'Frosted' scented geraniums (Pelargonium spp.) to replace the 'RADrazz' knockout roses and 'Munstead' english lavender (Lavandula angustifolia) to replace 'Hidcote' lavender.

Yet another concern was that the students had a month-long winter break when they were not able to monitor plants in the greenhouse. During this time period, horticulture staff managed the plant materialwatering, fertilization, transplanting, and controlling for pests and diseases, as well as moving plants to ensure the optimal temperatures and light levels - without the extra help of the Hort course students.

Sustainable nursery practices were implemented in the growing process. Peat-free, organic potting 


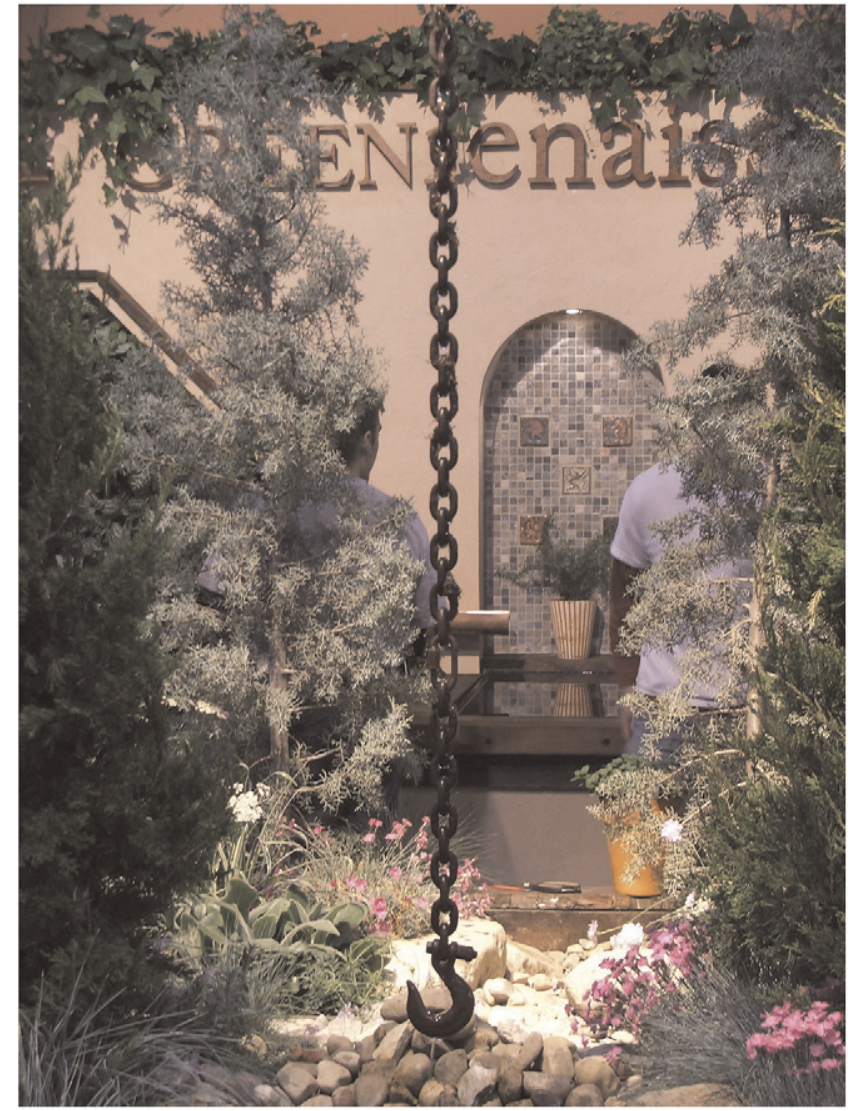

Fig. 5. Strategically placed plantings in the dry garden frame a view of a water table and a tiled niche in the terrace wall of Temple University's 2009 Philadelphia Flower Show exhibit. A rustic recycled chain and hook channel water from the aerial aqueduct to the dry streambed. Low water-requirement plants and recycled materials exemplify the conservation theme of the display (photo credit: J. Duffy).

soil from Organic Mechanics ${ }^{\circledR}$ (Modena, PA) was used to grow the vegetables for the kitchen garden. This soil is manufactured less than 35 miles from TUA. Plants went through many stages of stepping-up to larger containers. To reduce the amount of waste in this process, compostable fiber pots were used and added to our windrow composting operation at the Landscape Arboretum at TUA. As an alternative to chemical pesticides and fertilizers, horticultural oils and soy-based fertilizers were used as much as possible. Most of the vegetables and herbs were grown from seed in our greenhouses, decreasing the environmental impact of shipping full-grown plants. Daffodils (Narcissus spp.) were given a cold treatment in outdoor coldframes rather than in coolers to reduce energy use.

\section{Spring 2009: Implementation}

Designated as the design/build studio, the spring semester offered hands-on and "real world" learning experiences to the students. Planning, procuring, and estimating the cost of construction materials and tools involved delegation, coordination, and thorough documentation. A master schedule was prepared to facilitate purchasing, staging, transportation, personnel, and publicity.

This 5-week phase of work required the supervision of many groups of students spread over different locations at TUA, working simultaneously on numerous tasks. We had to find appropriate physical space required to build the larger components of the exhibit, such as the 10-ft-high and 12 -ft-wide terrace wall, 8 - $\mathrm{ft}$-high posts for the aqueducts, the bulky water table, and the green wall. Safe loading and transportation of these large and heavy features, using student labor, required careful advanced planning and on-site adjustments.

The building process required educating and enforcing basic rules of safety, such as using protective goggles, earplugs, and gloves (Fig. $7)$. Keeping track of all the equipment, supplies, and tools, and maintaining a well-organized working environment required constant vigilance and patience by the instructors. Having a well-equipped workshop and a centralized space dedicated to the flower show would have made the construction process much more efficient.

Students, staff, and faculty all participated in installing the display at the Philadelphia Convention Center during the last week of Feb. 2009 (Fig. 8). LA students started construction on the architectural and structural features such as the garden walls, water features, aqueduct, and green walls. After the structure was completed, the plant material was installed. Students worked in teams to organize and transport more than 3000 plants and install them in the appropriate locations using detailed planting plans. A main concern at this stage was protecting the plants in transit. Students packaged potted plants with paper sleeves, garbage bags, and newspapers, and transported them in a climate-controlled truck to protect them from the winter temperatures. This process required a great deal of teamwork, flexibility, and time management. At times, substitutions were made on the spot and the students used their judgment to determine the most appropriate plant layout. As this was a temporary display, plants remained in their pots, which were concealed with dyed sawdust mulch. Replacement plants were held in a storage unit in the Philadelphia Convention Center, and the remaining plant material was transported back to TUA to be installed in the Landscape Arboretum at TUA for the 2009 growing season.

LA students were responsible for organizing volunteers to staff the display during the show. They solicited help from the TUA community and held a training session to educate the volunteers. Each night, two volunteers watered the gardens and replaced any damaged or failing plants.

It is worth reflecting on the interdisciplinary design process that unfolded over time to make this work possible. It involved periods of uncertainty and confusion, followed by breakthroughs and elation. What 
Table 1. Signature plants of the four garden sections in the Temple University display at the 2009 Philadelphia Flower Show.

\begin{tabular}{|c|c|c|}
\hline & Common name & Scientific name \\
\hline \multicolumn{3}{|l|}{ Dry garden } \\
\hline & Arizona cypress 'Blue Ice' & $\begin{array}{l}\text { Cupressus arizonica } \\
\text { var. glabra }\end{array}$ \\
\hline & Maiden pink 'Feuerhexe' & Dianthus \\
\hline & English lavender 'Munstead' & Lavandula angustifolia \\
\hline & Lavender cotton 'Foxden' & Santolina chamaecyparissu. \\
\hline & Pincushion flower 'Butterfly Blue' & Scabiosa \\
\hline \multicolumn{3}{|l|}{$\begin{array}{l}\text { Vegetable } \\
\text { garden }\end{array}$} \\
\hline & Swiss chard 'Bright Lights' & $\begin{array}{l}\text { Beta vulgaris ssp. cicla var. } \\
\text { flavescens }\end{array}$ \\
\hline & Roman chamomile & Chamaemelum nobile \\
\hline & Lettuce 'Merveille de Quatre Saisons' & Lactuca sativa \\
\hline & Golden oregano 'Aureum' & Origanum vulgare \\
\hline & $\begin{array}{l}\text { Scented geranium 'Rober's Lemon } \\
\text { Rose', 'Dean's Delight', and 'Frosted' }\end{array}$ & Pelargonium \\
\hline & Rosemary 'Huntington Carpet' & Rosmarinus officinalis \\
\hline & Spinach 'Catalina' & Spinacia oleracea \\
\hline \multicolumn{3}{|l|}{ Green wall } \\
\hline & Button fern 'Lemon Buttons' & Nephrolepis cordifolia \\
\hline & Boston fern 'Bostoniensis' & Nephrolepis exaltata \\
\hline & Aluminum plant & Pilea cadierei \\
\hline & Candle plant & Plectranthus oertendablii \\
\hline & Purple heart 'Purpurea' & Tradescantia pallida \\
\hline \multicolumn{3}{|l|}{$\begin{array}{l}\text { Orchard } \\
\text { garden }\end{array}$} \\
\hline & Maidenhair fern & Adiantum pedatum \\
\hline & Serviceberry 'Autumn Brilliance' & Amelanchier $\times$ grandiflora \\
\hline & Lady fern & Athyrium filix-femina \\
\hline & Male Robust Fern & Dryopteris filix-mas \\
\hline & Eastern wood fern & Dryopteris marginalis \\
\hline & Ostrich fern & Mattenccia struthiopteris \\
\hline & $\begin{array}{l}\text { Foamflower 'Oakleaf', 'Running } \\
\text { Tapestry', and 'Brandywine' }\end{array}$ & Tiarella cordifolia \\
\hline & Highbush blueberry & Vaccinium corymbosum \\
\hline & Labrador violet & Viola labradorica \\
\hline
\end{tabular}

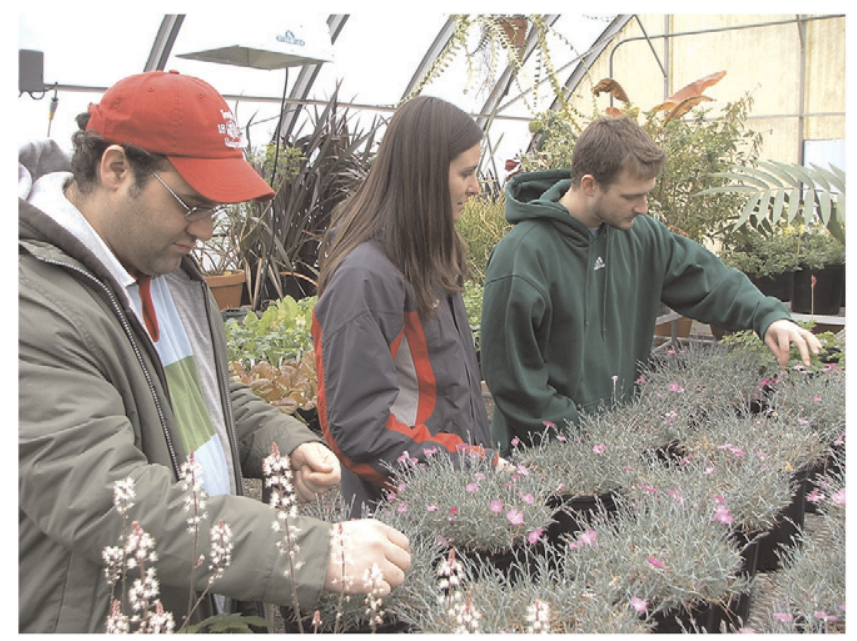

Fig. 6. Inspecting forced maiden pink, grown in the Landscape Arboretum at Temple University Ambler's greenhouse, are Horticulture Supervisor G. Chapman (center) with Directed Studies in Horticulture students J. Oyler (left) and J. Mull (right). These plants were part of the dry garden section of Temple University's 2009 Philadelphia Flower Show exhibit (photo credit: J. Duffy). appeared simple and logical in the final installation was often the result of hours and even days of struggle and deliberations.

This memorable experience extended the comfort zone of the students and promoted teamwork, creativity, endurance, and perseverance. It also involved resolving differences and disagreements, challenging both students and professors to rethink their own ideas. The whole process was exhausting as well as exhilarating and energizing, and the most rewarding aspect was a visible sense of achievement, confidence, and joy expressed by the students.

\section{Outcomes}

Promoting sustainability. The Philadelphia Flower Show exhibit process introduced new sustainable practices and products to the staff of the Landscape Arboretum at TUA. Because of this project, we have formed relationships with new local plant nurseries that share our ideals of sustainability; we have also adopted the practice of using organic potting soil and natural fertilizers. An intended outcome of the display was to illustrate to Philadelphia Flower Show visitors the idea that choosing native plant material, recycled and indigenous building materials, and using best practices can produce a beautiful, sustainable landscape.

STUDENT LEARNING. Students were asked to describe their learning experiences with special focus on sustainability, hands-on learning, and interdisciplinary education. The following is a sampling of their responses:

"We offered so many ideas for homeowners to use. Not only did we offer sustainable ideas, but we also showed that it could be done in a creative and aesthetically pleasing way...I felt our design was realistic, beautiful, creative, sustainable, Italian, and got lots of people, including myself, excited about creative gardening methods with a sustainable theme." C. Wood, LA student

"I enjoyed doing research on the different types of gardening that were combined within the flower show design, such as Italian gardening, sustainable gardening, using native plants and food plants. I especially liked researching xeriscaping and learning about the adaptations plants have in order to survive in drier environments, such as having grey-green coloring and thick waxy, cuticles." C. Harwick, Hort student 


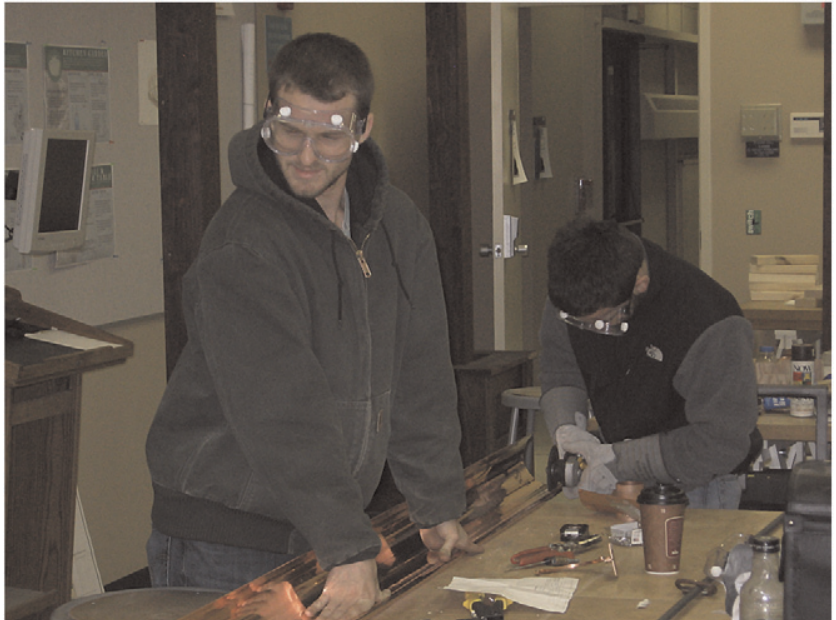

Fig. 7. Landscape Architecture students N. Petro (left) and M. Ford (right) work to construct a copper aqueduct that framed the entire Temple University exhibit and represented the conservation idea of rain water harvesting at the 2009 Philadelphia Flower Show (photo credit: J. Gleason).

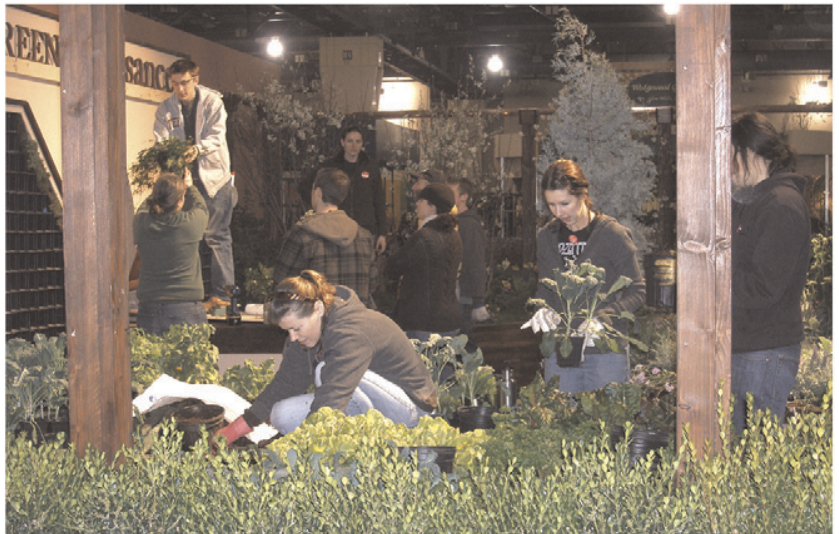

Fig. 8. Temple University students, staff, and faculty work to install plant material at the 2009 Philadelphia Flower Show (photo credit: B. Lamba).

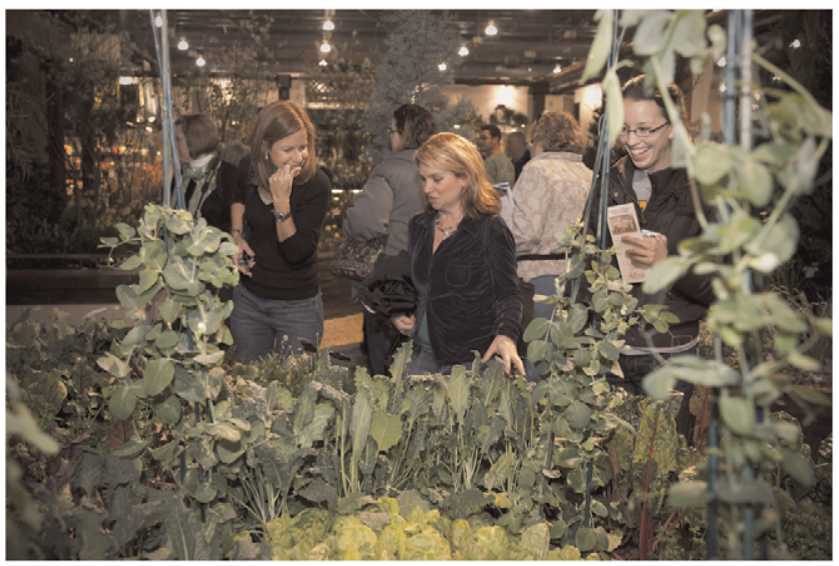

Fig. 9. Visitors to the 2009 Philadelphia Flower Show delight at the variety of plants in the kitchen garden, representing backyard food production in the Temple University exhibit (photo credit: B. Kelly).
"One important thing I learned about sustainable design is that being green in not easy. Finding stains, paints, paper, and wood that are environmentally friendly requires hours of research and travel, dozens of phone calls, and is just not as simple as running to the local hardware store. Much thought must go into the planning, design, building, recycling, and reuse of materials to end up with a product that is truly "sustainable." However, one thing that this experience has taught me is that sustainability can be beautiful, engaging and exciting... Understanding the implications of placing every $2 \times 4$, rivet and screw, are priceless lessons [that] will make me a better designer." T. Garret, LA student

"This was an invaluable learning experience of working with real budget, difficult deadlines, and complicated scheduling - giving you a taste of the real world." M. Ford, LA student

VISITOR RESPONSE. The experience and response of the visitors was an important part of our exhibit (Fig. 9). LA student volunteers for the show recorded comments made by visitors. A few selected comments are included here:

"The most popular piece that elicited the greatest attention was the rain chain in the dry garden. This feature caused most people to stop and acclaim how they would like add such a feature to their own gardens."

"Many visitors appreciated how our design evoked the Italian theme without using the cliche' of fake marble and wine bottles."

"People were absolutely amazed by the green wall, water table, and nichemost of them reached out to touch plants."

"Lots of people were really excited about walking into the exhibit and experiencing the barrage of smells that greeted them."

"People were getting and sharing ideas as to what they can do with various scraps around their homes, after seeing what we were able to accomplish using so many recycled materials."

"Visitors couldn't believe that students built all of this, and jaws dropped when told the time it took."

"One young woman asked questions for about $10 \mathrm{~min}$ about the physical construction of the aqueduct system and wanted to immediately start a similar one at her home.”

Awards. The display earned five awards from various organizations. These awards, focusing on design, plant choice, and sustainability, testify 
to the achievement of our core goal of demonstrating multiple ways of sustainable living: 1) Pennsylvania Horticultural Society Award of Distinction, awarded for second highest point score in the Academic Education category; 2) The American Horticultural Society Environmental Award, for an exhibit of horticultural excellence that best demonstrates the bond between horticulture and the environment, and inspires the viewer to beautify home and community through skillful design and appropriate plant material; 3 ) Special Achievement Award of the Garden Club Federation of Pennsylvania, awarded to an exhibit of unusual excellence in the category of conservation; 4) Men's Garden Club of Delaware Valley Award, awarded to a garden containing plants suited to the Delaware Valley in a setting that can primarily be maintained by one person; and 5) Philadelphia Unit of the Herb Society of America Inc. Award, for an outstanding use of herbs or an individual specimen herb.

\section{Follow-up}

The Philadelphia Flower Show lasts 1 week and then each display is deconstructed. Keeping with our commitment to sustainability, we took all of the hardscape and plant material back to TUA for reuse or responsible disposal. Many plants were installed in the gardens in Spring 2009 and the hardscape materials were recycled or reused when possible. The copper aqueduct will find a new use in the adaptive transformation of our historic headhouse into a new visitor center for the Landscape Arboretum at TUA. The wood from the aqueduct posts will be used in various construction projects at TUA.

This phase of the flower show work also involved looking back at the hands-on construction experience and using this knowledge to prepare a complete set of construction documents. These documents can be used by a contractor to build this design. Presentation materials that can be used for publications, design portfolios, and potential award submissions were also prepared by the students.

\section{Conclusions}

Undertaking a collaborative, interdisciplinary, and hands-on project requires a high level of commitment from the administration, cooperation and coordination among the faculty, and the support of the entire staff. In spite of the logistical challenges associated with this teaching model, its educational benefits were well worth the effort. The project broke down disciplinary boundaries and promoted critical thinking and holistic problem solving while promoting the overall mission of conservation, environmental responsibility, and sustainability.

\section{Literature cited}

Klein, J.T. 1990. Interdisciplinarity: History, theory and practice. Wayne State University Press, Detroit.

Levine, A. and R. Rogers. 2003. The Philadelphia Flower Show. Harper Resource, New York.

Resnick, L.B. (ed). 1989. Knowledge, learning and instruction: Essays in honor of Robert Glazer. Erlbaum, Hillsdale, NJ.

Temple University. 2009. Office of Sustainability: Creating a sustainable campus culture. I June 2009. <http:/ / www.temple. edu/sustainability/>. 